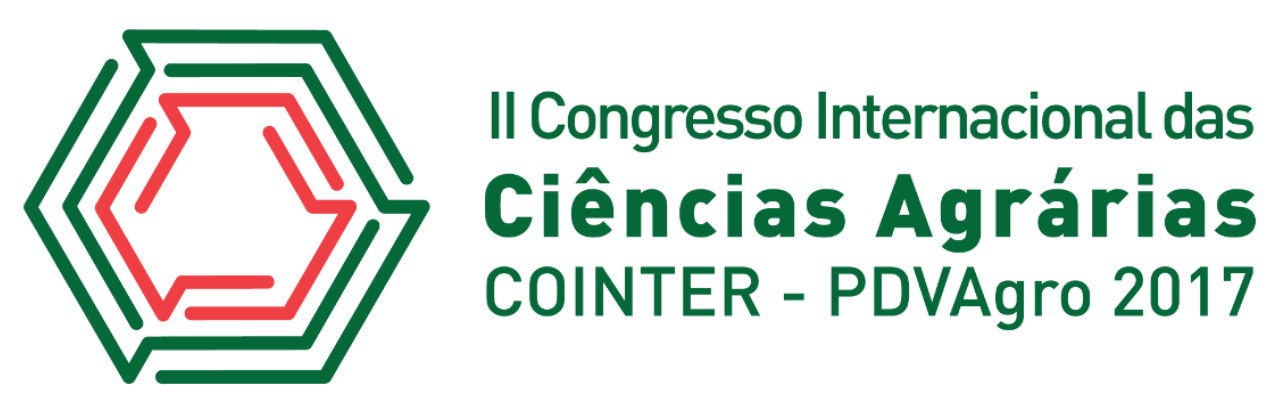

\title{
ANÁLISE COMPARATIVA DE ÁREAS DEGRADADAS EM ÁREAS PROTEGIDAS NO ASSENTAMENTO DOM PEDRO II- BOA SAÚDE / RN
}

\author{
Apresentação: Pôster
}

Stephanni Ingrid de Souza Silva ${ }^{1}$; Yanka Beatriz Costa Lourenço ${ }^{2}$; Elias Costa de Souza ${ }^{3}$;

\section{Introdução}

O desmatamento de mata nativa se deve aos modos de produção e ocupação da terra. A caatinga é um dos biomas brasileiro que sofre com o processo de desmatamento e desertificação, isso ocorre devido aos fatores socioeconômicos e culturais. Com a falta de políticas publicas que facilitem a vida no campo e com poucos recursos, o homem explora a Caatinga com o intuito de retirar a lenha para vender e abrir áreas para as atividades como a pecuária, os plantios, retirada de minério etc. (NEVES, 2006; EVANGELISTA, 2011). De acordo com o INPE, uma área de Caatinga, de aproximadamente $90 \mathrm{mil} \mathrm{km}^{2}$, foi mapeada. Essa área corresponde a 9,15\% do total da Caatinga, onde $40 \%$ dessa área apresenta uma característica preservada, $45 \%$ degradada, 7,2 \% de solo exposto e $6,5 \%$ de lavoura (BRASIL, 2015).

Apesar da legislação brasileira ser bastante complexa, alguns fatores, como falta de materiais e meios para investigar o desmatamento, fazem com que não haja boa eficiência no seu cumprimento. Com isso, o geoprocessamento se torna um meio aplicável para suprir as deficiências relativas às atividades de vistoria, realizadas pelos órgãos ambientais, auxiliando de maneira decisiva a investigação da adequação do uso da terra em áreas de preservação permanente, reserva legal ou de uso restrito (TOWNSHEND, 1992; XAVIER-DA-SILVA, 1992; AULICINO ET AL., 2000; COSTA ET AL., 1996).

O objetivo deste trabalho foi analisar o grau de desmatamento num assentamento, comparando imagens de diferentes anos.

\footnotetext{
${ }^{1}$ Engenharia Florestal, UFRN, stephanniflorestal@gmail.com

${ }^{2}$ Engenharia Florestal, UFRN, yankalourenco97@gmail.com

${ }^{3}$ Engenheiro Florestal, UFRN, eliasrem@hotmail.com
} 


\section{Fundamentação Teórica}

Realizando a análise comparativa nas áreas de reserva legal e preservação permanente do assentamento Dom Pedro II- Boa Saúde/ RN, em diferentes anos, pode-se estimar a área que fora degradada e, com base nas áreas degradadas do ultimo ano, podemos apresentar soluções para a recuperação das mesmas.

\section{Metodologia}

Foram utilizadas imagens, do Google Earth Pro, referente aos anos 2013 e 2016, onde criou- se polígonos nas áreas degradadas, dentro da Reserva Legal e na Área de Preservação Permanente do Assentamento. O perímetro do assentamento foi disponibilizado pelo INCRA. Após isso, calculou- se as áreas degradadas nos respectivos anos e nas tipologias de áreas de proteção, com o intuito de realizar uma análise comparativa da degradação do solo nos anos em estudo. Com as imagens, realizou- se uma planta do assentamento Dom Pedro II, utilizando o QGIS 2.14.12.

\section{Resultados e Discussões}

Foram obtidas, em hectare, as áreas degradadas da Reserva legal e da APP do assentamento Dom Pedro II - Boa Saúde / RN. A Figura 1 mostra o grau de desmatamento nas áreas protegidas, anos de 2013 e 2016. O ano de 2016 apresentou maior grau de desmatamento, isso se deve a ocupação do assentamento.

Figura 1. Mapa com as áreas de desmatamento nas áreas naturais protegidas do assentamento Dom Pedro II (Lado esquerdo referente ao ano 2013; lado direito referente ao ano 2016). Fonte: Própria.

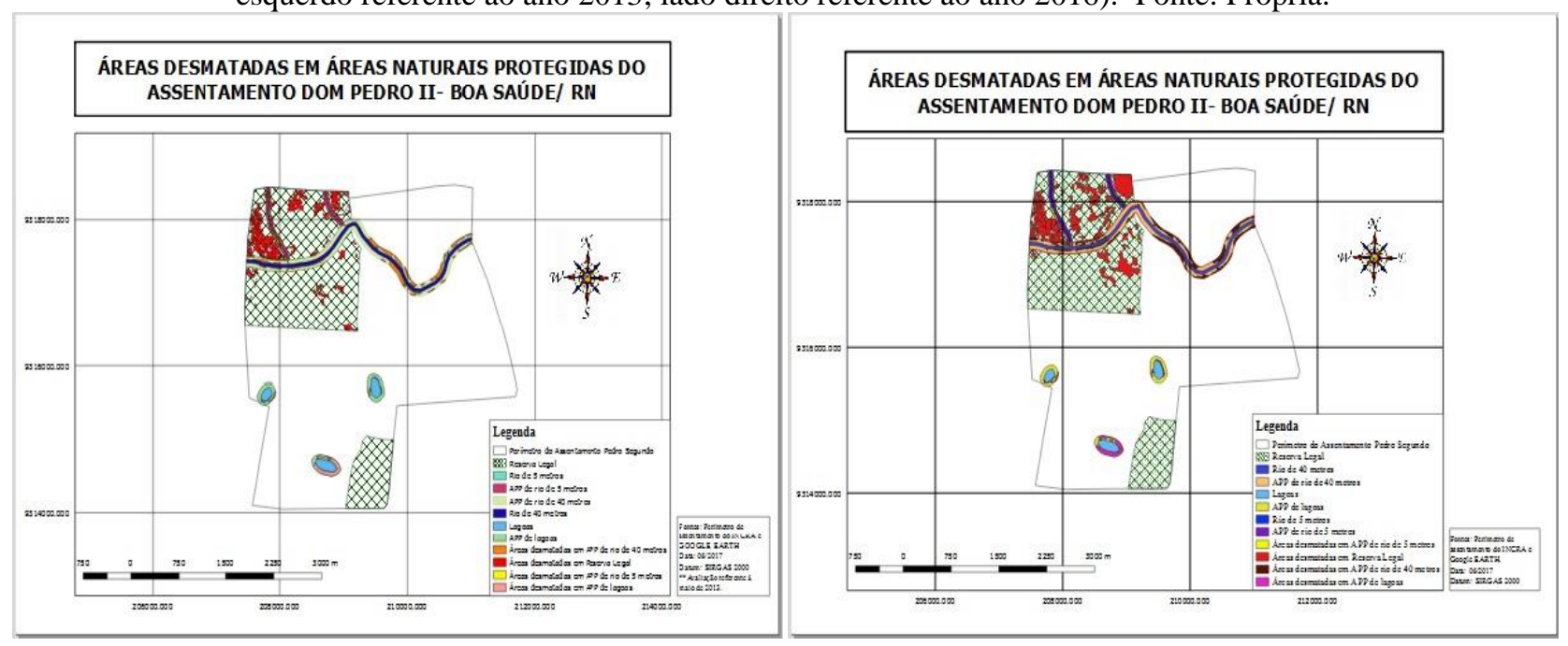


A maioria dos assentamentos no Estado não possui uma assistência técnica e social eficiente, principalmente para à criação de atividades que gerem renda ao produtor rural, sendo assim, o homem tende a procurar outros meios para adquirir renda para o sustento da família, um deles é o corte da lenha para venda ou próprio consumo. O problema é que, por falta de conscientização ambiental e, também, por falta de agilidade dos órgãos públicos, o homem do campo se vê tendo que violar as leis ambientais. Analisando a imagem do ano 2016, percebemos que as áreas desmatadas posteriormente ao ano 2013, foram muito próximas às áreas que já estavam desmatadas, isso se deve a facilidade de se adentrar a mata com a presença das picadas, trilhas de acesso.

O assentamento foi entregue no ano 2012 pelo INCRA para as famílias rurais. De acordo com os moradores do assentamento, antes de se tornar propriedade do INCRA, a área pertencia a um fazendeiro, onde o mesmo utilizava o local para atividades como pastoreio. Com a procura por água é um fator limitante para a criação de animais, a área de preservação permanente foi bastante afetada, além das áreas ao redor da mesma, isso facilitou o acesso durante os anos para se adentrar mais a mata, não só pelos animais como pelo homem, causando assim a erosão do rio. De acordo com os assentados, hoje as famílias possuem dificuldades para obter água do rio, não só devido ao assoreamento do mesmo como a presença de uma barragem que possui em Boa Saúde/ RN.

Foram calculados as áreas totais das áreas naturais protegidas e as áreas desmatadas, com isso, gerou-se a porcentagem das áreas desmatadas em relação as áreas totais (Tabela 1). O ano de 2016 apresentou um percentual de 9,89\% a mais que o ano de 2013 na reserva Legal, seguido de $6,32 \%$ a mais na APP do rio de 40 metros, 0,55 \% a mais na APP de lagos, com exceção da APP do rio de 10 metros, que apresentou no ano de 2013 a maior taxa de desmatamento, 6,91\% a mais que 2016.

Tabela 1. Área total, área desmatada e porcentagem das áreas protegidas do Assentamento Dom Pedro II- Boa Saúde/ RN, referente aos anos 2013 e 2016. Fonte: Própria.

\begin{tabular}{lcccccccc}
\hline & \multicolumn{3}{c}{ Reserva Legal } & \multicolumn{2}{c}{ APP rio 40 metros } & \multicolumn{2}{c}{ APP lagos } & \multicolumn{2}{c}{ APP rio 10 metros } \\
\cline { 2 - 9 } & 2013 & 2016 & 2013 & 2016 & 2013 & 2016 & 2013 & 2016 \\
\hline Área Total (ha) & 285,28 & 285,28 & 49,97 & 49,97 & 23,49 & 23,49 & 11,02 & 11,016 \\
Área Desmatada (ha) & 33,46 & 61,69 & 20,7 & 13,85 & 4,42 & 4,55 & 1,7 & 0,04 \\
Porcentagem (\%) & 11,73 & 21,62 & 21,41 & 27,73 & 18,82 & 19,37 & 15,43 & 8,52 \\
\hline
\end{tabular}




\section{Conclusões}

A forma de ocupação da terra e como ocorreu, antes por um único proprietário e após o ano da entrega por meio do INCRA para as famílias rurais, foi a fator limitante para o desmatamento na região. Antes a terra era demandada para o pastoril, de apenas uma família, hoje, mais de 40 famílias fazem o uso da terra, sendo assim, há uma pressão maior para que as famílias possam se manter no local. Cabem então, ao INCRA e aos órgãos ambientais facilitarem a vida do homem no assentamento, disponibilizando assistência técnica, projetos de educação ambiental, de recuperação de áreas degradadas e dando agilidade aos processos para os assentados poderem dar início as suas atividades no campo. Com isso, e realizando vistorias, aliadas ao uso de ferramentas de geoprocessamento, haverá ao longo prazo a diminuição do desmatamento de forma ilegal e em áreas protegidas, além da autorregeneração das áreas passíveis de tal.

\section{Referências}

AULICINO, L.C.M; RUDORFF, B.F.T; MOREIRA, M.A; MEDEIROS, J.S; SIMI JÚNIOR, R. Subsídios para o Manejo Sustentável da Bacia Hidrográfica do Rio Una através do uso de técnicas de Geoprocessamento e Sensoriamento Remoto. In: SIMPÓSIO LATINO AMERICANO DE PERCEPCIÓN REMOTA, 9., 2000, Puerto Iguazu, Missiones, Argentina. Anais. Argentina, 2000.

COSTA, T. C. C., SOUZA, M. G., BRITES, R. S. Delimitação e caracterização de áreas de preservação permanente por meio de um Sistema de Informações Geográficas (SIG). Revista Árvore.Viçosa - MG, v.20, n.1, p.129 - 135, 1996.

EVANGELISTA, Antonia dos Reis Salustiano. O processo de desmatamento do Bioma Caatinga: Riscos e vulnerabilidades socioambientais no território de identidade do Sisal, Bahia. Revista Geográfica de América Central, Costa Rica, v. 2, n. , p.1-13, jul./dez. 2011. Semestral. Disponível em: <http://www.redalyc.org/articulo.oa?id=451744820490>. Acesso em: 03 out. 2017

NEVES, Ana Carolina Marzullo. Determinantes do desmatamento na mata atlântica: Uma análise econômica. 2006. 86 p. Dissertação (Pós-Graduação em Economia da Indústria e da Tecnologia)- Universidade Federal do Rio de Janeiro, Rio de Janeiro, 2006. Disponível em: <http://www.ie.ufrj.br/gema/pdfs/mono_Ana\%20Carolina\%20Marzullo.pdf>. Acesso em: 02 out. 2017.

TOWSHEND, J. R. G. Environmental database and GIS. In: MAGUIRE, D.J., GOODCHILD, M.F., 14. RHIND, D.W. Geographical information systems: principles and applications. New York: Longman Scientific \& Technical, 1992. p., p. 201-205.

XAVIER DA SILVA. Geoprocessamento e análise ambiental. Revista Brasileira de Geografia. v. 54, p. 47-61, 1992. 